дозволяє розглядати канон як необхідну основу для богослужбової-співочого творчості.

Ключові слова: канон, канонічна форма, богослужбової-співоча традиція, культ, церковність.

Osadchaya S. Phenomenon and concept of the canon as basis of orthodox liturgical and singing tradition: from the initial form to «spirit of creativity». Article is devoted to consideration of the phenomenon and concept of a canon as bases of orthodox singing tradition. Comes to light that the initial form should be understood as the form created in tradition, in life of a canon and under his direct influence that allows to consider a canon as a necessary basis for liturgical and singing creativity.

Keywords: canon, initial form, liturgical and singing tradition, cult, churchism.

Стаття надійщла до редакції 27.04.2016

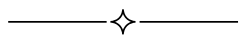

УДК $78.01+78.03$

\title{
А. Овсянникова-Трель \\ ЭРОС И ЭТОС КАК ОБРАЗНЫЕ ДОМИНАНТЫ И ЦЕННОСТНЫЕ ОРИЕНТИРЫ МУЗЫКАЛЬНОГО ИСКУССТВА
}

В статье обсуждается проблема воплощения образов Эроса и Этоса в музыке в аспекте культуротворческой функции музыкального искусства. Специально выделяется специфика художественного преломления образов Эроса и Этоса в академической и популярной музыке в контексте продуцирования ценностных ориентиров и смыслов культуры. Предлагаются направления культурологического исследования образов Эроса и Этоса как образных доминант и ценностных ориентиров музыкального искусства.

Ключевые слова: Эрос, Этос, музыкальное искусство, культурные ценности, академическая музыка, популярна музыка.

Музыка как форма культуры является механизмом отражения и продуцирования ценностных смыслов бытия человека. Соответственно, она неизбежно связана с базовыми основаниями человеческого сушествования, этическими по своей природе, и, в частности - отношением к Другому, взаимоотношением с Другим, потребностью «делиться собой» с Другим, в осознании своей абсолютной ценности для Другого, а также приятия себя этим Другим. Этическими - потому,

(C) Овсянникова-Трель А., 2016 
что только посредством Другого (Другой в качестве повода и причины) может реализоваться моральный и нравственный потенциал отдельно взятого человека. Причём в качестве Другого могут быть совершенно различные величины: от Мира, Жизни в целом - до отдельно взятого человека. Все эти посылы составляют смысловое ядро тех явлений, которые обычно определяют как Любовь (или же Эрос, её частный случай - одну из разновидностей Любви) и Этос, который в данном случае неотделим, ибо они сращены в своей первопричинности.

Как известно, в древнегреческой философии Эрос понимался универсально - это и чувственная любовь, и телесное влечение, но это и любовь к Прекрасному. У Платона Эрос, являясь космической силой, пронизывает всё сушее: отношения между полами, религию, философию, художественное творчество, ибо его главное дело «рождать в красоте», он - «всевластная мировая сила» [3, с. 65].

Такой смысловой универсализм понятия Эроса открывает очень широкие возможности его художественного воплощения, преображения его посредством музыкальной выразительности. Вечные темы и вопросы, волнующие человека как биологический вид, с одной стороны, и как творца культуры, с другой, во все времена волновали и музыку, которая способна чутко реагировать на самые сокровенные стороны человеческого существования.

Данный материал является попыткой наметить те смысловые векторы, которые могут указать путь для культурологического взгляда на проблему воплощения Эроса и Этоса в музыке как важнейшей формы создания ценностных ориентиров и смыслов культуры, такой пёстрой и многогранной в своих проявлениях, особенно сегодня. Однако для успешного осуществления этой попытки необходимо определиться в понятиях и терминах, которые будут задействованы в процессе обсуждения.

Первое. Категории академической и популярной музыки, которые понимаются в традиционном противопоставлении музыкально-профессиональной традиции специального образования (композиторского и исполнительского) и отсутствия такового. То есть речь идёт о разделении музыки на ту, которая была создана композиторами-профессионалами и исполнена профессиональными музыкантами, и ту, которая является результатом «любительского» творчества. Соответственно речь идёт: в количественном отношении о «музыке меньшинства» и «музыке большинства», в качественном (в смысле слушательской аудитории) - музыке «для избранных» и музыке «для всех». 
Сегодня эти грани стираются, говорить о массовой культуре (и музыке в частности) некорректно, поскольку современные интегративные и кросскультурные тенденции в мировом и европейском культурном пространстве породили ситуацию принципиальной гомогенности музыкальных процессов. Популярная музыка сегодня демонстрирует удивительные примеры профессионализма, специальной обученности сочинению конкретных типов музыки, востребованных среднестатистическим слушателем (феномен хита), и даже производить её в качестве продукта массового потребления (шаблонное производство «топовой» музыкальной продукции - хитов, специальный цех композиторов, создающих киномузыку в Голливуде, маркетинговые основания музыки в рекламе и т. п.). В самых престижных европейских и американских музыкальных университетах и колледжах колоссальным спросом пользуются факультеты, на которых можно обучиться мастерству звукорежиссёра и мастеринга трека - производству эталонного носителя, копией которого является потребительский носитель аудиозаписи (CD-диск, виниловая пластинка и т. п.).

И наоборот, те сферы популярной музыки, которые по своим художественным показателям являются высочайшими образцами музыкального искусства как такового или, по крайней мере, огромное количество её представителей, которые расцениваются (и музыкантами-академистами в том числе) как эталоны музыкального профессионализма, - не имеют профессионального образования и являются уникальными примерами автодидакта.

Второе. Понятие образной доминанты подразумевает количественно превосходящую все остальные сферу художественных образов в музыке (в сравнении с базовыми для искусства и связанными с самыми главными темами человеческого существования - Жизнь, Смерть, Любовь и т. д.), и сам образ как механизм воплощения объективно-абстрактных идей в звуковую реальность. «О Любви» - основная тема музыки, её «вечная тема», как и искусства в целом, и во многом его исток: мы знаем огромное количество историй о том, как «влюбился - и написал», «ничего не чувствую, не влюблён - не могу написать», вплоть до известных сентенций Г. Нейгауза-педагога о том, что «...когда влюбитесь - придёте на урок и будете играть». Всё это - свидетельство созидательной, космической силы Эроса, о которой говорили древние и которая очень упрощена сегодня. Именно по этому поводу Б. Вышеславцев писал, что истинная любовь трансцендирует за пределы чувственного влечения 
и ищет полноты в бесконечности. Бесконечности чего? Творчества. Отсюда - идея этики преображённого Эроса, т. е. этики творчества по Б. Вышеславцеву [1].

Современные искусствоведческие концепции часто рассматривают Музыку как специфическую форму выражения онтологических оснований человеческой жизни, в том числе её культурных смыслов и ценностей, воплощённых посредством музыкального языка и образности. Так, в концепции «Духовного анализа музыки» В. Медушевского [5] заложен прямой выход на музыкальную онтологию - т. е. на идею изначальной способности, а главное - потребности! музыки воплощать посредством широкого арсенала своих средств выразительности сущность Бытия (человеческого в том числе). Речь, по большому счёту, идёт о единственно возможном предназначении музыки как формы культуры и человеческой деятельности. Собственно, это реабилитация самых ранних форм музыковедческого дискурса, отличающихся целостностью и универсализмом. Хотя и в более близкие нам исторические эпохи подобные мысли возникали: «Что есть музыка, если не течение самой жизни и не отражение её тайны постоянного движения... Музыка выражает бытие самого бытия» (из «Натурфилософии» Шеллинга); «Рождение звука с трудом подаётся объяснению» (Ф. Гегель) [2].

Обсуждаемые две разновидности музыкальной культуры - академической (серьёзной, профессиональной высокой, классической) и популярной (лёгкой, развлекательной, массовой) органично соединяются в концепции музыкальной онтологии: поскольку их субъектом и объектом является человек, ценностная система его мировоззрения и культуротворческие потребности. И тема Любви (или уже - Эроса) занимает здесь далеко не последнее место. Показательны и симптоматичны в этом плане современные культурологические подходы к популярной музыке, которые рассматривают её в прямом отношении к «..эротическому, интимному переживанию в современных обществах...» [6, с. 88] и связывают такой взгляд на «музыку большинства» с тем обстоятельством, что «...сосредоточенность на интимности в поп-музыке двадцатого века была обусловлена значительными изменениями в потребительском сознании, исходила она, прежде всего, от молодой аудитории, преимущественно женского пола, ищущей в поп-музыке любви и романтики» [6, с. 89].

По В. Медушевскому, в музыке реализуются три сущности человека - духовная, душевная и плотская (исходя из христианской 
богословской концепции человека), соответственно - человек духовный, человек душевный и человек телесный (плотский) творит музыку и отражается в ней как в зеркале. Первое (духовное, человек духовный) - этическая доминанта серьёзной музыки и её онтологическая идея (по В. Медушевскому), вторые две - пространство лёгкой музыки (по В. Медушевскому и преобладающему количеству теоретических выкладок современного музыкознания). Все три позиции имеют прямое отношение и к Эросу, и к Этосу, поскольку эти два понятия являются тем онтологическим вместилищем, которое хранит многообразие проявлений духовного-душевного-плотского, и является экзистенциальным поводом для проявления этих ликов человеческой сущности. Логично задаться вопросом: на каких уровнях могут рассматриваться воплощения Эроса и Этоса в музыкальной культуре? И присутствуют ли принципиальные различия между художественными установками академической и популярной музыки в этом вопросе? Постараемся наметить наиболее очевидные аспекты данной проблемы.

Исторический аспект. Каждая эпоха расставляет свои акценты в соотношении Эроса и Этоса, в понимании ценности того и другого для жизни человека. Душа как средоточие переживаний, и особенно переживаний любви не во все времена осознавалась музыкой. XVIII век стал началом новых объектов интересов музыки: «мощное вторжение мира чувств в мир звуков воспринималось как творческий стимул, как источник неувядаемой молодости...» [4, с. 104-105]. Хотя уже композиторы Ренессанса стремились средствами музыкальной выразительности запечатлеть движения души, взволнованной переживанием любовного чувства (так называемый «взволнованный стиль» мадригалов К. Джезуальдо и Монтеверди). Европейская аристократическая рыцарская культура, и представляющая её музыка в лице трубадуров, труверов, миннезингеров - «певцов любви» - даёт целую эпоху культа Эроса, реализованного в культе Прекрасной дамы (парадоксально соединяющего в себе возвышенно-духовные переживания и их эротически-чувственные нюансы).

Романтическая концепция Эроса выдвигает понимание его как «интимной области духа, души, чувства» (в формулировке Гегеля), которое может быть единственно возможным выражением собственно духовного в искусстве [2, с. 253]. Любовь мыслилась как истинная красота духа, и поэтому любовь - это «идеал романтического искусства» [2, с. 254]. Образы Эроса составили онтологический смысл ро- 
мантической музыки, именно они мыслились наиболее адекватным выражением божественного в музыке, абсолютным проявлением божественной идеи мироздания, поскольку «Бог есть Любовь». Этой идеей пропитан огромный массив европейской профессиональной музыки от конца XVIII века.

Или же ситуация в популярной музыке XX века, для которой многообразие образов Эроса стало идейной доминантой и смысловым ядром самовыражения «культуры большинства». Речь идёт о двух магистральных направлениях неакадемической музыки прошлого столетия - рок- и поп-музыке. В обоих случаях «песни о любви» занимают центральное место в содержательно-тематическом плане, но вот понимание этой любви весьма разнится. Два этих направления воплощали и формировали две противоборствующие этики, касающиеся любви, и особенно телесно-чувственного её образа. Попмузыка ценила долг, обязательство, верность и веру в возвышающее и облагораживающее воздействие Эроса, рок же настаивал на тотальной свободе и честности личностного самовыражения (что, конечно же, было продиктовано социокультурными идеями современности, сексуальной революцией в частности; см. об этом отдельную главу книги Д. Хезмондалша [6]).

Этнокультурный аспект. Еще одним срезом является разнообразие музыкально-художественных преломлений Эроса и Этоса в различных национально-культурных традициях, ибо каждая национальная картина мира (в формулировке Г. Гачева) предполагает своё понимание нравственности, морали и Любви. В музыковедении эта тема пока ещё не освоена, но литературоведение, благодаря исследовательскому энтузиазму Г. Гачева, осуществило ещё в конце прошлого столетия интересный опыт научного подхода к национальным вариантам Эроса, выпустив сборник публикаций под названием «Национальный Эрос в культуре» (1995). В нём отмечены те конкретные характеристики образов Эроса в литературных произведениях, которые обусловлены ментальностью того или иного народа (славянская жертвенность и покорность, французская пикантность и изысканность, итальянская и испанская страстность и т. п.). Подобный подход может быть применим и к музыкальной культуре, которая в каждом из своих национальных вариантов предлагает «своё» видение этого онтологического основания жизни человека.

Образно-смысловой аспект. Сквозную линию в академической музыке образует идея возвышенной и жертвенной любви, о которой в 
своё время так пафосно высказывался Гегель: «Подлинная сущность любви состоит в том, чтобы отказаться от сознания самого себя, забыть себя в другом «я» и, однако, в этом исчезновении и забвении впервые обрести самого себя и обладать собою» [2, с. 253]. С уверенностью можно говорить, что это действительно образная доминанта серьёзной музыки, утверждающая духовное измерение Эроса как универсальной созидающей силы. Искусство оперы даёт яркие и совершенные образы, воплощающие эту идею. Чио-чио-сан, Лю, Снегурочка - преимущественно женские образы, персонифицирующие бескорыстную возвышенную любовь, жертвуюшую собой во имя счастья Другого.

Так, например, образ служанки Лю в «Турандот» Дж. Пуччини воплощает идею нравственного величия и «тихого», «малого» героизма женской натуры. Бескорыстная любовь к принцу Калафу и стремление к его счастью (не своему!) приводит маленькую Лю к кровавому финалу своей жизни (вполне в духе веристской драмы). Именно благодаря её поступку во взаимоотношениях Турандот и Калафа всё складывается благополучно. И этический облик великодушного татарского принца Калафа в этом смысле становится не совсем «благородным», поскольку он этот факт совсем не берёт во внимание. Лю, считая Калафа смыслом своей жизни, тем не менее скрывает свою любовь - она ведь знает, что принц не может стать мужем рабыни. Кроткая, смиренная, но в то же время стойкая, Лю живет для других: её самоотверженность бесконечна, она осознана и нравственно аргументирована, и жертва, которую она приносит ради любимого человека, понимается ею как единственный вариант, когда «всем будет хорошо».

Трагическая история молодой японки Чио-Чио-сан, ставшей женой американца Пинкертона и оставленной им с маленьким сыном, также преломляет идею жертвенности. Но в данном случае это откорректировано материнским статусом главной героини. Образ Чиочио-сан, несмотря на свой веристский исток, совершенно лишен натуралистических проявлений. Её сценический облик не выстроен в опоре на «эмоциональный надрыв» страдающих героев веристских новелл, наоборот - этот женский образ предельно облагорожен и «аккуратен» в своей психологической выразительности. Это объясняется, конечно же, иным, в отличие от европейского, восточным обликом Женщины, которая просто по определению не может быть открыта эмоционально в соответствии с нормами этикета. Но можно предположить, что это внутреннее благородство и эмоционально- 
психологический тонус образа Чио-Чио-сан обусловлены ещё и тем, что в опере она представлена не только как любящая женщина, но и как мать. Самоубийство героини - это результат осознания своей беспомощности и бесполезности в судьбе своего сына, ведь только его отец может обеспечить ему будущее по законам своей страны. Жертва маленькой гейши, внешне лишённая всякого пафоса, по сути своей обретает колоссальный этический смысл - это полное самоотречение, полное отсутствие эгоизма во имя Блага тех, кто дорог.

Героини, подобные Лю и Чио-чио-сан, демонстрируют поразительные возможности музыки в воплощении этической стороны Эроса: способности к жертвенности во имя высшей справедливости и благ других, тех, кого они любят. Подобные персонажи оказываются субъектами совокупности отношений и представлений, несших печать нравственной ответственности за свои поступки, помимо социально регламентированных поведенческих стереотипов «цивилизованного» общества.

Образ Снегурочки из оперы Н. Римского-Корсакова - своеобразный манифест христианского понимания Любви. В христианстве Эрос очищается и преображается действием благодати, пряча чувствительность под слоем чувственности. Но чувствительность к чему? К духовному в человеке, открывающемуся посредством Эроса. В. Медушевский по этому поводу пишет: «...Невозможно противиться бессмертной красоте её духа, божественной любви, как она явлена в музыке, особенно в предсмертной арии блаженства, полной бескорыстной любви ко всем, хотя теплейшей - к Мизгирю!» [5, с. 97]. А далее музыковед рассуждает о концептуальном противопоставлении идеи Любви, воплощённой в образе Снегурочки, тому языческому чувственно-эротическому идеалу, который персонифицирован в фигурах Леля и царя берендеев.

Эрос как стихийная, восторженная влюблённость, в виде почитания, направленного на объект любви, в избытке воплощена в классике академической музыки: Ленский, Ричард, Тристан и Изольда, Ромео и Джульетта, Зибель, Тамино... Это перечисление можно продолжать бесконечно. Что объединяет все эти образы, каждый из которых, конечно же, обладает своими нюансами в раскрытии идеи Любви? Уже упомянутая чувствительность к духовной сущности переживаемого чувства, которая перекрывает чувственную его сторону. Человек духовный возвышается во всех этих случаях над человеком плотским. И даже душевная сторона (переживания, широчайший 
спектр эмоций) не является главной в смысловой содержательности этих оперных героев, поскольку речь идёт о высоте их Духа, преображённого Эросом.

С количественной точки зрения образы, персонифицирующие собственно страсть, в которой доминирует чувственная сторона Эроса, явно будут уступать первым. Их можно попытаться перечислить: Хозе, граф Ди Луна, Скарпья, Саломея, Катерина, Грязной. Ещё меньше музыкально-образных воплощений Любви как игры (ludus), одной из её разновидностей, о которой также говорили древние, пытаясь классифицировать это явления. Даже если попытаться отнести сюда такие персонажи как Кармен и Дон-Жуан, которые, на первый взгляд, кажутся именно таковыми - эта оценка окажется несостоятельной, поскольку каждый из них гораздо сложнее и глубже своей внешней стороны. Большинство же оперных образов европейской музыкальной классики - обнаруживают именно глубоко этический смысл Любви.

В популярной музыке этого нет в таких масштабах, вместо этого есть огромная шкала переживаний любовного чувства: от душевноэмоционального до чувственно-телесного. Эстрадная песня, в меньшей мере - авторская песня и то, что сегодня определяют как «попса», изобилуют сквозными, «вечными» сюжетами, актуальными для каждого человека: несчастная любовь, измена, страсть, разлука, конец любви и т. д. и т. п. Градации душевных переживаний и чувственных страстей - колоссальны, художественный уровень поэтического текста и, как следствие, музыкального образа - примитивны в сравнении с академической музыкой. На первом плане - душа человеческая, либо страдающая, либо пребывающая на вершине блаженства. По большому счёту, общий знаменатель поп-музыки - тотальная погружённость в душевную жизнь человека, одержимость чувствами и чувствованием. Чувствованием чего? Эмоций и тела, которые так остро переживает Эрос. И здесь - справедливое замечание В. Медушевского: «лирика без духа стала бы эстрадой» [5, с. 385].

И тогда закономерным становится исполнительский аспект. Условность и одухотворённость музыкально-сценического (визуальнозвукового) выражения, отодвигающего «в сторону» натурализм эмоциональных реакций и телесность как несущественные компоненты музыкально-художественного образа, преимущественно характерны для академической музыкально-исполнительской традиции (оперы, в первую очередь). На идее пре-поднесения духовной сущности, преображающей буквальность и реалистичность музыкального об- 
раза, выстраивалась традиция европейского исполнительского мастерства. Музыкально-исполнительские высоты в этой традиции связаны именно с умением «приподнять» музыкальное выражение и музыкальную выразительность над обыденными человеческими представлениями о жизни и её различных проявлениях, в том числе о Любви, возвысить саму идею этой стороны человеческого существования до её этического смысла. Естественным оказывается здесь и основной «инструмент» воздействия на слушателя: индивидуальная исполнительская техника, в основании которой - владение музыкальным инструментом (любым музыкальным или своим голосом) и актёрское мастерство (если речь идёт о вокальном искусстве). И такое исполнение «музыки о Любви» (будь это оперная ария, вокальный цикл или фортепианная пьеса) не нуждается в дополнительных средствах выразительности, поскольку в художественной полноте поэтического текста и особенно музыки уже заложена одухотворённость исполнительского выражения.

И напротив, гораздо более простые поэтические тексты и музыка «о Любви» в «попсе», сегодня доходящие до абсурдности в своём примитивизме, провоцируют совершенно противоположный принцип исполнительского выражения, который активно задействует «дополнительный» рычаг воздействия на слушателя - визуальный, и который становится основным. Идея телесности сосредоточена в концепции внешнего облика исполнителя - яркого и часто вызывающе плотского, предлагаемого в качестве образа сексуальности. Визуальная сторона исполнительского выражения, акцентирующая внимание на внешнем (тело как зрелище), отодвигает «в сторону» внутреннее - собственно музыку (музыкальная выразительность как смысл). Именно такая концепция Эроса породила феномен «поющих трусов», за которым стоит не только название украинской женской поп-группы, но и сам принцип исполнительской формы целого потока топовой музыкальной продукции современности (как зарубежной, так и отечественной).

Безусловно, сводить популярную музыку к «попсе» нельзя: наряду с этой её крайней формой существуют и другие направления (эстрадная и авторская песня), которые предлагают совершенно иной вариант исполнительского воплощения образов Эроса. В этом варианте визуальный фактор не столь существенен, а собственно музыкально-выразительный, реализованный в исполнительском мастерстве певца, является основанием художественного выражения (фран- 
цузский шансон, классика советской эстрадной песни, бардовская песня и т. п.). В недрах неакадемического музыкального искусства известны уникальные примеры исполнительских концепций, в которых органично соединены внешнее и внутреннее, зрелище и исполнительское мастерство, тело и голос, духовное, душевное и телесное - то единство, которое художественно адекватно и полноценно воплощает универсальный смысл Эроса (феномен Фреди Меркури).

Обобщая все эти рассуждения, необходимо отметить следующее.

Эрос и Этос, нераздельные в своей онтологической основе, составляют очевидную в своей значимости образно-смысловую сферу музыкальной культуры. Они запечатлены в богатейшем разнообразии музыкально-художественных воплощений, в музыке серьёзной и лёгкой, в музыке для избранных и «для всех». Это - «вечная тема» музыки, как и искусства в целом, как и человеческого существования вообще. Безусловно, эта образная доминанта музыкального искусства требует специального изучения, которая, вероятно ещё только ждёт своего исследователя. И если в отношении академической музыки эта тема косвенно очень часто затрагивается музыковедами и культурологами, то популярная музыка практически оставлена «за бортом» исследовательского интереса, поскольку часто расценивается как недостаточно полноценная в художественном плане. Но, как известно, именно популярная культура, пространство массового сознания наиболее быстро и точно схватывает те ценностные смыслы, которые наиболее актуальны на том или ином этапе человеческой истории. И хотя по безапелляционному мнению В. Медушевского «...изучать низменное - значит поддерживать его лживый авторитет... и настаивать на внеценностном...» [5, с. 383], необходимо осознавать тот факт, что несоответствие популярной музыки высоким художественным стандартам академического искусства имеет не только негативный смысл своей «неполноценности». Лёгкость и доступность, доходящая до примитивизма (особенно сегодня) ставит перед исследователем весьма трудные задачи обнаружения «большого» смысла в легкодоступном художественном материале, который существует в пространстве культуры просто по другим законам, нежели серьёзная музыка. И для кого-то нет ничего серьёзней простой «песни про любовь», которую он слышит по радио или телевизору и которую слышат ещё тысячи таких же как он. А всё потому, что каждый из этих тысяч в более чем простой мелодии распознаёт свои душевные волнения, свои эмоции, свой жизненный опыт, свой образ Эроса. 


\section{СПИСОК ЛИТЕРАТУРЫ}

1. Вышеславцев Б. Этика преображённого Эроса / Б. Вышеславцев. М. : Республика, 1994. - 368 с.

2. Гегель Г. Эстетика : в 4 т. Т. 2 / Г. Гегель. - М. : Искусство, 1969. - 326 с.

3. Лосев А. Боги и герои Древней Греции / А. Лосев, А. Тахо-Годи. - Харьков : Фолио, 2009. - 349 с.

4. Малиньон Ж. Ж. Ф. Рамо / Ж. Малиньон. - Л. : Музыка, 1983. - 124 с.

5. Медушевский В. Духовный анализ музыки : учебное пособие : в двух частях / В. Медушевский. - М. : Композитор, 2014.

6. Хезмондалш Д. Музыка. Почему она так важна для нас : [пер. с англ.] / Д. Хезмондалш. - Харьков : Изд-во Гуманитарный Центр Олива И. В., 2014. $-240 \mathrm{c}$.

Овсяннікова-Трель А. Ерос і Етос як образні домінанти і ціннісні орієнтири музичного мистецтва. У статті обговорюється проблема втілення образів Eроса і Етоса в музиці в аспекті культуротворчої функції музичного мистецтва. Спеціально виділяється специфіка художнього заломлення образів Ероса і Етоса в академічній і популярній музиці в контексті продукування ціннісних орієнтирів і смислів культури. Пропонуються напрямки культурологічного дослідження образів Ероса і Етоса як образних домінант і ціннісних орієнтирів музичного мистецтва.

Ключові слова: Ерос, Етос, музичне мистецтво, культурні цінності, академічна музика, популярна музика.

Ovsyannikova-Trel A. Eros and Athos as figurative dominants and values of musical art. The article discusses the problem of the embodiment of the images of Eros and Athos in music in the aspect of the cultural function of musical art. Specifically, the specificity of the artistic refraction of the images of Eros and Ethos is singled out in academic and popular music in the context of the production of value orientations and meanings of culture. The directions of cultural studies of the images of Eros and Athos as figurative dominants and values of musical art are suggested.

Keywords: Eros, Ethos, musical art, cultural values, academic music, popular music.

Стаття надійила до редакції 11.05.2016

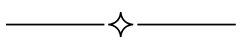

